DePauw University

Scholarly and Creative Work from DePauw University

$10-16-2020$

\title{
The sonic aesthetics of writing: Pedagogy, timbre, and thought
}

Derek R. Ford

DePauw University, derekford@depauw.edu

Follow this and additional works at: https://scholarship.depauw.edu/educ_facpubs

Part of the Education Commons

\section{Recommended Citation}

Ford, D.R. (2020). The sonic aesthetics of writing: Timbre, pedagogy, and thought. Pedagogy, Culture and Society, online first.

This Article is brought to you for free and open access by the Education Studies at Scholarly and Creative Work from DePauw University. It has been accepted for inclusion in Education Studies Faculty publications by an authorized administrator of Scholarly and Creative Work from DePauw University. 


\section{The sonic aesthetics of writing: Pedagogy, timbre, and thought}

Derek R. Ford, DePauw University

7 E. Larabee St.

Harrison Hall 218

Greencastle, IN 46135

derekford@depauw.edu

315-491-6987

ABSTRACT: While research on the educational properties of sound have opened up important pathways for research, there is a tendency to approach sound through meaning and information. This paper charts another tendency to explore sound as educational precisely because it resists our attempts at meaning making, thereby moving us from the process of understanding to the experience of thought itself. The force that guides this trajectory is that of timbre, or the nuance of sounds. I begin with Nina Sun Eidsheim's, which aims to delink timbre from essence and identity by showing the infinite potential of vocal timbres. While Eidsheim surely weakens the link, the pedagogy she articulates remains within the drive to produce knowledge and under the aesthetic of the beautiful. To experience timbre's pedagogical charge requires a move to the aesthetic of the sublime. To make this move, I link together Jean-François Lyotard's writings on writing, thinking, aesthetics, and sound, which allows expansive conception of timbre and shows the sonic dimensions of writing and thinking, through which the writer suspends their drive to know and becomes passible to the timbre (or phoné) of the word.

Keywords: writing, sound, Jean-François Lyotard, sublime, Nina Sun Eidsheim 
The sonic aesthetics of writing: Pedagogy, timbre, and thought

\section{Introduction}

Sound has always been a concern for education. From silence and dialogue to the role of music and song, the sonic dynamics of education and the educational dynamics of the sonic have, over the past decade or so, become a more explicit concern in educational research. While this work has opened up various important paths, there is a tendency to approach sound as meaningful. Sound is educational because it is a process of transmitting information from which we can express, interpret, attend to, and generate meaning. There is nothing objectionable about this tendency, but by reducing sound to meaning we miss experiencing the matter of sound. Accordingly, in this paper I want to chart another tendency to explore sound as educational because it not only resists our attempts at making meaning, but more importantly because it grasps us and disseizes or desubjectifies the educational subject. Disseizure is educational because it moves us from the process of understanding and generating knowledge to the experience of thought itself.

The primary charge I follow here is that of timbre or the nuance of sounds, the qualities of sounds that exceed our capacity to identify and know. I begin with recent conceptualizations of educational sound, which thus far haven't considered timbre as a pedagogical force, before moving to Nina Sun Eidsheim's (2019) latest book on vocal timbre. Eidsheim shows the problems that arise from associating timbre with an essence or identity and from positioning it as a knowable entity. One's vocal timbre is voiced and heard as an expression of an identity. To the extent that these identities are produced by oppressive regimes, such a voicing and hearing naturalizes and reinforces them. In response, she works to weaken the link between timbre and essence, opening timbre up to its infinite potentialities. By listening to our listening, we no longer ask after the source of the voice's timbre, and instead ask ourselves why we are listening and hearing as we are. Her pedagogical proposal hinges on the deconstruction of timbre, which reveals that any meaning generated from timbre can be open to relentless questioning, which can generate new meanings. The limitless potential of timbre, that is, is revealed by the endless actualizations (names, meanings, and knowledges) we can ascribe to it. While this surely weakens the link between timbre and essence, it remains within the drive to produce knowledge and, as I later show, under the aesthetic of the beautiful. The moment of disseizure is ultimately eclipsed by a return to the subject organized along the lines of development. Lingering within meaning deprives us from experiencing timbre qua timbre, the infinite indeterminacy of a sound as such, an experience that takes place under the aesthetic of the sublime.

To push timbre's pedagogical dynamics into the sublime, I link together Jean-François Lyotard's writings on writing, thinking, aesthetics, and sound. Connecting timbre with literacy allows an expansive conception of timbre and shows the sonic dimensions of writing and thinking, which for Lyotard are always processes of listening. I begin this section with Lyotard's distinction between modern re-writing and re-writing modernity. In the former, the writer returns to a zero point in order to correct errors, erase stray marks, expose faults, and generate new knowledges. In the latter, the writer suspends their drive to know and becomes open to the force of timbre, which suspends the mind and allows the subject to touch what he calls the clouds of thought. The rest of the paper continues to work through this distinction by focusing in on the form and timbre of words, or their lexis and phoné, and then re-writing Lyotard's notion of modern re-writing to place it under the order of the beautiful. Here, the point isn't to get to the 
truth but, like with Eidsheim, to produce ever more knowledge about modernity. By re-writing modernity under the order of the sublime, on the other hand, the writer is faced with the very ability to conceptualize, know, and understand, and as such is open to the matter of thought and timbre qua timbre.

This project reverberates with recent moves to problematize and decenter the category of the human, notions of human agency, and hierarchical binaries between subjects and objects. Here, the mattering of the human - and particular kinds of humans — comes at the cost of disavowing, discrediting, and eliminating other kinds of matter. Knowledge is crucial in producing, reproducing, and working against these ontological hierarchies, as we struggle over the borders between legitimate and illegitimate knowledges: what and who does or doesn't make what kind of sense? By attending to matter, a range of scholarly research - from posthumanism to affect theory - work to challenge and reconfigure regimes of agency and what groups and beings can participate in knowledge production, as well as what constitutes knowledge, legitimate or otherwise (e.g., Mulcahy, 2012; Reddington and Price, 2018; Snaza and Karavanta, 2015; Zembylas, 2017). In the classroom, this sonically takes the form of a struggle over what constitutes noise (nonsense) and what constitutes sound (sense), whereby the sounds of those not admitted the (full) status of agent are literally and figuratively heard as noisy, as too loud or too soft, incomprehensible, irrelevant, or inauthentic, and are variously repressed or excluded. To not just include these sounds, but to reconfigure the realms of ontology, epistemology, and the audible necessitates new conceptions and pedagogies of literacy, hearing, and listening under the sublime so that matter (including bodily matter) can appear on its own terms.

The problem with maintaining literacy and sound under the order of the beautiful is that it keeps education locked in the drive to identify, produce, and develop knowledge through grasping. In Poetics of Relation, Édouard Glissant (1997) writes that "the verb to grasp contains the movement of hands that grab their surroundings and bring them back to themselves. A gesture of enclosure if not appropriation" (191-192). Matter are positioned only as potential sources of new knowledge for pedagogy to uncover and make transparent, and the subject is positioned as that which is capable - and duty bound - to do so. With the sublime, however, matter in all of its opacity and the unknowability - the timbre of words - disable the subject's capacity to grasp, understand, and to produce knowledge, opening the possibility of inaugurating a new order of being together.

\section{Sounding education}

In their editorial introduction to a special issue dedicated to forming a distinct subfield of educational foundations called "sound foundations," Walter Gershon and Peter Applebaum (2018) observe that sound in educational research is most often used mimetically by, for example, using deploying sonic metaphors to describe or approach dynamics. As such, sound foundations, which is a deep and sustained conversation between the motely field of sound studies and educational research, has to move past metaphors and engage sound on its own terms through "sound methods, ways of using the sonic as research tools regardless of how understandings from the information gathered are expressed, as sounds or text for example" (361). Sound methods don't elevate sound to the top of a new educational hierarchy, but rather investigate the particularities inherent in them.

Sounds are, as Gershon (2011) elsewhere puts it, "educational systems" because they are

"sensual data so rife with information that the listener can render often disparate-seeming sounds 
into embodied meaning systems" (66). Writing in the context of curriculum theory, Gershon here challenges the dominating tendency to approach everything - including sounds - as text. The sounds that prevent or inhibit such a reading are, accordingly, dismissed or framed as impediments, whereas Gershon argues that they "are indeed educational in that they convey meaning to the listener and systemic in that the listener places those meanings into conceptual categories that inform their understandings" (76). Sounds open meaning up through resonance (as any sound can resonate with anything) and reverberation (sound is always moving). As a result, we're "fluxed," and if we acknowledge this then "resonance suggests that any perspective is given the dignity of attention in that it (a) resonates with that person at that time and (b) for reasons they believe to be important" (Gerson 2018, 2). By tuning research into the intention, attention, and expression of sounds, we can better appreciate the political nature of listening to sound at the same time as we overcome the division between the emission and reception of sound and open education up to the blurred distinctions and outsides of our current frameworks.

Thus far, literature that we might group under sound foundations has stretched educational research and practice in important ways, such as by investigating the aural dimensions of inequality and oppression, exploring teaching as a practice of conducting voices, and expanding our understanding of what voices are, and who and what "has" a voice (e.g., Forrest 2015; Mazzei and Jackson 2017; Schwarz-Franco 2018 Wargo 2018; Wozolek 2018). Additionally, educational research has pushed beyond the privileging of voice and the unidimensional Western conception of silence as mere absence, lack, and disengagement, and the corresponding privileging of talking and student voice (e.g., Ford 2014; Hao 2011; Zembylas and Michaelides 2004). Thus far, the sonic and pedagogical potential of timbre hasn't been theorized as an educational potentiality. Given the relatively new status of both sound studies and sound foundations, this is unsurprising. While timbre is prevalent in sound research, including traditional music and music education, it too is often left unambiguously and problematically open. This ambiguity is precisely where its sonic pedagogical value lies, and thinking through the educational dynamics of timbre can enrich both fields broadly. The present article contributes to the burgeoning pivot around sound and pedagogy by considering these dynamics. By attending to the sonic properties of literacy — of writing, reading, and thinking - I approach literacy not as processes that can be grasped by sound metaphors, but as practices of listening and hearing that, as vibratory enactments, disable our ability to grasp.

Relative to childhood literacy, Michael Gallagher, Abigail Hackett, and Lisa Procter (2018) have demonstrated the limits of confining literacy pedagogy to the "auditory comprehension of recognizable, representational vocabulary" (465). While the decontextualization and abstraction of literacy pedagogy from operations of power have been critiqued, learning to speak and listen are still reduced to the acquisition of the ability to voice and hear linguistic representations, the problems of which are most evident in early childhood given the prevalence and importance of nonlinguistic sounds. These sounds, they argue, "ought to be valued as part of children's expressive and communicative practices, and as a vital force in how they forge relations with the wider world, rather than merely a precursor to words" (465). Children, in effect, can teach adults to unlearn our listening practices to attend to the vibrations that exist beyond any association with words and that are variable, ephemeral, and nonlocalizable. Confining sound to the mere communication of meaning by, for example, teaching children that "water splashes and twigs crack" (469) attunes our attention to words attributable to specific materials only, instead of the actual vibratory and relational movements that exceed any particular object. Sounds are "a kind of everyday magic" that are "available for all kinds of 
actions, signals, meaning-making, power games, imaginative play, and monstrous fantasies" (480). Sounds here are still, however, raw materials for the imagination and the mind to grasp. Although the essence of sounds are opened up beyond language, they are still framed as potential knowledges for, and at the service of, the subject. My wager, however, is that sounds, including the sounds of text, are educational precisely because they are beyond meaning, and that to actually experience sounds we have to suspend our minds and become open to the passing charge of timbre. In other words, the pedagogical sonic force of writing comes from the matter of words themselves.

\section{The pedagogy of timbre}

Timbre is an elusive and ultimately impossible category that is approachable only as a present absence or an unidentified difference. Timbre is the difference that makes it possible for a listener to discern the difference between two sounds with the same pitch, duration, and intensity. In her study of vocal timbre, Nina Sun Eidsheim (2019) locates crucial political and pedagogical problems that emerge from our engagement with timbre, and specifically the gap between the potentiality of timbre and its particular actualizations and manifestations, or between the openness of timbre and the demand for identification and categorization.

Eidsheim (2019) introduces this by way of the acousmatic question that the listener is asked: what or who am I hearing? This question assumes that we can discern an answer, identify a source, and generate knowledge about the source (person) and the sound (voice). Yet the very reason for asking the question is because we can't formulate an answer; "we ask the question because voice and vocal identity are not situated at a unified locus that can be unilaterally identified" (3). She turns the question around so it is asked of the listener's listening: "Who am I, who hears this?" (24). Timbre isn't a knowable thing but a process. By naming and measuring sounds, we block the infinite potentiality of timbre by insisting on limited concrete actualizations. While timbre is an errant phenomenon that can't be pinned down, it "is often used to make truth claims about voice and the person emitting the vocal sound" (5). This means, in turn, not only that (vocal) timbre is seen as a unique and genuine product of an identifiable subject, but also that the pedagogy of timbre - how we come to voice and listen - reproduces systems of oppression, to the extent that "the practice of essentializing vocal timbre is the unexamined foundation upon which racialized vocal timbre is maintained" (154).

Both in formal and everyday settings, "we are conditioned to hear what we listen for and to assume that what we hear is indisputable" (50), so that when "we subsequently hear them, and because we hear them, we believe the perceived meaning to be verified" (51). This is most evident when there's a gap between what we're listening for and what we hear. One striking example she offers is of Angelina Jordan, a young Norwegian girl, performing a Billie Holiday's "Gloomy Sunday." The disbelief and shock that strikes the audiences (on the TV show on which Jordan performed, in the audiences where Eidsheim has presented her research, and Eidsheim's own) is the disruption of the belief that the voice is an essential expression of a unique identity. Because Holiday's voice has been essentialized as the expression of Black suffering and her own particular autobiography, it's heard as an expression of a story of Blackness and her own story of hardships, tragedy, and so on. How could this young girl from Norway then sound so similar?

The disruption is pedagogically powerful but also ambiguous. On the one hand, it can strengthen our commitment to timbre as essence. Here, "the listener holds an image of an original voice in his or her mind, comparing it with the evidence available as a more or less 
favorable reproduction with a greater or lesser degree of fidelity" (164). In other words, timbre as timbre isn't heard. But on the other hand, the relationship between timbre and essence can be weakened. When we hear "both the voice of the singer at hand and that voice inflecting the idea of the imitated voice," we should be moved "to question the very foundation upon which the assumption of vocal essence rests" (165). The pedagogical task, then, is to listen to our listening. For Eidsheim, this pedagogy consists "of demonstrating that the practical experience of exploring more of the wide range of timbral potential inherent in each voice offers a perspective on any single timbre" (57) so "that every timbral quality or meaning may be interrogated" (58). Timbre itself, as a limitless potentiality, doesn't possess or communicate any meaning; instead "any and all meaning is generated outside the form" (184). This doesn't mean foreclosing the political, but rather holding politics in tension with potential. When we realize that "a collection of styles and techniques is distinguishable through one name, it may also be distinguishable through another name, and another, and another, and yet another" (193). The infinite potentiality of timbre is manifested through each particular actualization.

If timbre's pedagogical force rests in its limitless potentiality, which can manifest through the limitless process of assigning words to it, then what is the relationship between the word and timbre? Chasing this question, I think, can not only intensify the break between essence and timbre and sound out new pedagogical potentials, but also help us lend an ear to literacy, to writing, reading, and thinking, thereby breaking the link between literacy and knowledge and returning literacy to thought. In doing so, we can escape the drive to knowledge and meaning that predominates in sound studies and even in Eisheim's pedagogy. While listening to our listening by opening up the interpretations of timbre, we remain within the drive to produce meaning and knowledge. Timbre as a force without or beyond meaning remains inaccessible; so too does potentiality and, as we will see with Lyotard, thought.

\section{Re-writing modernity: Listening to the timbre of words}

Lyotard could be approached as a writer who writes in order to think about writing. In a 1986 lecture series at the Wellek Library at the University of California, Irvine, he references how Claude Simon answered the question posed by someone from the Union of Soviet Writers about what Simon thought writing is, to which Simon replied, according to Lyotard (1988), "It consists in trying to start a sentence, to continue it, and to finish it" (4) Writing, in other words, is an attempt to go someplace through and with the writing, to try and begin, to try and continue, and to try and end. This attempt "constitutes thinking or writing in its "entirety"" (7). Writing is, for Lyotard, not synonymous with thinking but a practice through which one can access thought. To emphasize that one can only try to write intimates that writing is not an instrument to be wielded, a technique to be learned, or a mechanism to be mastered. It's not a process of transcribing existing knowledge from the ear onto paper or screen or of formulating representations to reality competently. Nor does the attempt to write emanate from the will, as if there is an "I" who has a thought or sensation and is compelled to organize it linguistically to communicate it to others. That one can only try to write sentences means that the sentence is always incomplete. Thus, it's not a matter of trying harder or writing better, but of surrendering to the impossibility of writing. This is not - or not only - due to the permanent disjuncture or difference between reality and language, the real and the symbolic, the unconscious and the conscious, or, in proper Lyotardian speak, discourse and figure, but instead to the very inability to think. Thought's constitution will be gestured towards more throughout the paper, but at this point I'll say that thinking is most 
sharply distinct from knowing or understanding, the latter of which come under the property of the mind and are the result of the subject's grasping of data, and the former of which is an exposure to that which is beyond the mind's capacities.

To approach the matter from the heading with which he is most commonly associated, we can go to Lyotard's paper on "Re-writing Modernity." The heading was given to Lyotard by the organizers of a conference in Milwaukee, and for him it's better than postmodernity because it changes the "post" to a "re" and "modernity" to "writing." Lyotard prefers the first change because it eschews any pretense to periodization, to declaring another end and another beginning, which is a definitively modern (and impossible) gesture. Indeed, in a later work he will define modernity as the endless piling up of new willed pronouncements of new inaugurating periods. The "re" indicates a return that is simultaneously present, past, and future. To understand his preference for writing, we have to appreciate his distinction between two kinds of re-writing. The first is re-writing as remembering. This is a modern re-writing through which the writer returns to the beginning of the text or the top of the document and begins again. One draft is finished and the next draft is begun. The point of modern re-writing, and the point of modernity, is to mark a new zero hour in which the mistakes, misinterpretations, and mystifications of the past can be corrected, and the unknowns can be grasped to produce new knowledge. By marking a new zero hour, we can get closer to the zero point of the truth, justice, equality, and freedom. Modern re-writing produces progressively more comprehensive knowledge, as drafts move along the progressive path from potential knowledge to actualized knowledge.

As opposed to modern re-writing, re-writing modernity is re-writing as working through. This re-writing is "without end and therefore without will: without end in the sense in which it is not guided by the concept of an end-but not without finality" (30). One tries to finish or complete the writing but can only ever succeed in ending it. Without the will to guide it, the writer here operates under Freud's rule of free-floating attention, which "states: do not prejudge, suspend judgement, give the same attention to everything that happens as it happens" (30). Rewriting as working through, in other words, is propelled not by the will but by "listening to a sentiment. A fragment of a sentence, a scrap of information, a word, come along" (31). The objective here is not to know or understand, but to think. The point is not to gather more data to write a more accurate representation, but to experience the forces that limit and mobilize the subject's capacity to synthesize and even, perhaps, to remain as a subject.

Modern re-writing is based on the progression from opacity to transparency, from an unknown known to a known known, while re-writing modernity is a non-developmental way to approach opacity as such. Opaque matter is not only incapable to being rendered transparent, but actually disseizes the subject. Writing is therefore an aesthetic practice or, as Lyotard will prefer to say at times an anasthetic practice, one that doesn't come from feeling but from the surplus of feeling, a surplus that is felt negatively as a limit. Because of the dominant framing of hearing and listening as cognitive understanding (in which we listen for what we can hear), it might be helpful to follow the thread of listening that Lyotard introduced in the paper. Although Lyotard frequently equates writing and reading with listening and sound, or writes about the former as actions of the latter, the scattered and fragmentary nature of the remarks itself requires some working through.

As Lyotard hints above, writing always involves listening, and just as there are different modes of writing, so will there be different modes of listening and sounding. There are, in other words, multiple "voices of voice." A substantive categorization here comes from Lyotard's 
writing on voices in the analytic scene, from which he draws on Aristotle's differentiation of lexis and phoné. Lexis is the articulated voice, which "is formed by articuli, by little members deprived of signification in themselves, which can refer to the objects they designate because they are their arbitrary representatives" (Lyotard 1991, 128). This is the voice that literacy teaches children to speak and to hear to inaugurate them into the classroom community, in which the speakers and listeners agree on the correspondence between language and referent through constant interchange. To listen for lexis is to listen for inflexions of voices, or the degree or character of a voice's divergence from an alleged zero state. The voice is that of an addressor who uses words to communicate information to an addressee. The analyst is tasked with uncovering the true nature of this information. Modern re-writing is a practice of listening for the inflexions of lexis to approach the zero point of the origin. The result isn't merely a new draft to be rewritten, but a new end and a new beginning: "we've made a real breakthrough today," or "you're finding your voice!" The teacher is positioned as a subject authorized to either affirm existing knowledge or help the student produce new knowledge.

There is another voice, phoné, that doesn't inflect because there is no zero point of meaning or origin from which to deviate. Instead of varying by degree, it jumps. It's not articulated or arbitrary, isn't involved in the transmission of information, and doesn't have senders or receivers. It makes sense and signals only itself. This, of course, means that phoné is hard to "articulate" because it is "supposedly inarticulate" (130). The phoné is the timbre or nuance of the voice and the word. As a timbre, it's always indeterminate relative to any categorization of sound. It's a singular emission of matter that isn't concerned with reference and is impossible to locate within an order of meaning. As a timbre, we hear why phoné is difficult to articulate through writing. Because we can't know it, we can't properly hear it.

Lyotard goes so far as to say timbre is mute. The root of mute, $m u$ or mut, appears in a range of words that denote "the sound obtained by closed lips: to moan, to mutter, murmeln, murmerer, mugir;" mu even shows up in the word "word" in French: mot (Lyotard 1992, 130). For Aristotle, phoné is a property of all animals, and humans are those who have both phoné and lexis. With the former, we present presence, our affectivity and animality, while with the latter we communicate, exchange, and produce meaning. The reason why phoné is mute is because "it always muffles the lexis" (130), it always covers over and obscures meaning. With children (those who can't speak lexis) and animals, phoné appears as phoné, and literacy is the process of repressing phoné to birth lexis. With the speaker of words, phoné appears most often within lexis, as that which "can infiltrate a given place in the articulated structure, a given linkage, without being heard, precisely without inflecting the good order, and thus without having to reflect it" (133). It isn't heard because it's mute and isn't destined for an addressee. Literacy pedagogy is a practice of listening for the phoné of words, for that which can't be heard so that matter can appear as such.

The pedagogical mode that can make this possible is the technique of free-floating attention. Lyotard finds that Freud moved to this pedagogical mode in response to the problematic of phoné as it manifested in the case of Ernst, or the "Rat Man." When Rat Man reports to Freud that his parents knew a thought he had, but which he didn't articulate, Freud at first tries to reduce the phoné to lexis because he's trying to hear the zero degree of the voice. He does so by taking up the position of the addressee in a position of knowing in order to put the rules of exchangeable discourse in force, so that Rat Man and Freud can uncover the truth. With the shift to free association, however, Freud loosens his role as knower and abandons his place in the exchange of lexis, which gives the timbre of the voice and the word a greater presence. The 
inaudible timbres appear in his notes during and after the session, which now constitute a rewriting of the scene. "All writing," Lyotard tell us, "is this attempt to bear witness, by way of the articulated lexis, to the inflexible phoné... a debt of affect which it despairs of ever being able to pay off' (138). The writer is no longer the one who wills the truth to master and know the formerly unknown word, and instead one who suspends the will and competency to receive the phoné. In the classroom, teachers and students are no longer trying to grasp the meaning of the words or their voicing to hear them, but to listen for the noise of both, a noise that is sovereign in its own right.

It might appear that literacy is not about the transmission of information or the communication or generation of meaning, and is instead concerned with accessing that which is outside of and underneath representation. Yet this is no romanticization or infatuation with an excessive surplus. After all, Lyotard writes with language, and I'm writing about that writing. As Lyotard (1988) says in his Wellek Library lectures, we can't approach thought through "aggressive autonomy" or "spontaneous fantasy" (19). And interestingly he criticizes one of his early books, Libidinal Economy, on precisely the grounds that he gave into the spontaneous fantasy "of inscribing the passage of intensities directly in the prose itself without any mediation at all" (13) that emanated from "the temptation of indifference" (15). Putting this sonically, because timbre is the sounding difference of everything except duration, pitch, and loudness, without the latter qualities there is no everything except.

As such, we write not only with language but also against it. If we only write with language, we remain within the circuits of exchangeable discourse and knowledge. We can still generate new knowledge, of course, but we remain resolutely under the confines on understanding and, as a result, inaccessible to thought. Language and writing are both allies and rivals, and modern re-writing doesn't constitute writing for Lyotard because there is no adversarial relationship; writing is totally submissive to language, and the subject remains within the grasping drive. Re-writing modernity is when one disobeys language to get beyond the pitch, duration, and loudness of words and into their timbre: "One violates it, seduces it, one introduces into it an idiom unknown to it" (Lyotard 1992, 89). We don't write because we know what to say, but to think about what else there is beyond the said, and how it might leave its trace in the text. Literacy isn't the practice of actualizing potential knowledges through new drafts and readings, but of trying to think by surrendering to the matter of words; of trying to let words disseize the subject.

\section{The sublime sounds of writing}

At this point, the question of who or what it is that writes with and against language remains. If writing involves accessing something beyond my ability to understand, then is it still "me" who writes? Lyotard says that writing doesn't come from the writer's will, but is there a force determining the movement of my hands on the keyboard right now? Because writing is a sonic process, it makes sense to frame it as an acousmatic question. The question of what or who writes, then, is one we ask of ourselves while writing. It's a question that modern re-writing can answer, or claim to answer: I am the knower or seeker of truth. For Lyotard, it's a question that can't be answered because any answer would remain trapped within the order of meaning, representation, and knowledge. It's not a question to answer, but a question to think. In his paper on re-writing modernity, Lyotard (1991) suggests in passing that writing happens "under a problematic of the sublime as much as, and today more than, more obviously than, the 
problematic of the beautiful" (33-34). This is a helpful way to frame the acousmatic writing question because the difference ultimately hinges on the role, presence, and composition of the subject and its relationship to grasping, understanding, and thought.

According to Kant, a judgment of the beautiful is one of taste. A judgment of taste is disinterested (not based in empirical or practical commitments), purposeless (there is no need fulfilled), singular yet universal (we judge taste for ourselves but because it is disinterested everyone should agree with us), and without guarantee (there is no concept we can identify with it). Taste is therefore not knowledge but the possibility of knowledge. When we encounter a form that is beautiful, Lyotard (1994) writes, "it is as if the dissonances that divide thought, those of the imagination and the concept, were on the wane and left way open" (20). This openness accounts for the pleasurable feeling of the beautiful. In an encounter with the beautiful, we can only imagine how the object or experience could be given a concept, accorded a form, or made into knowledge. We experience the power of our faculties at play with each other. They can play because they are disinterested and not driven by any ends. The beautiful activates the imagination. While the beautiful is "only regulative and not determinant in effect," the "activity is the activity of understanding, the faculty of determining" (58).

I want to suggest that the aesthetic of modern re-writing, then, is the pleasure felt by the imagination's confrontation with an unknown. We experience some excess in the narrative, which propels our imagination to consider the endless ways that it could be made into a new kind of knowledge. Because modern re-writing is "the activity of understanding," there is ultimately a closure of thought through the production of knowledge. The writing subject is "in a state of infancy" (20) or is "a minimal subject," "a barely subjective subject" $(1988,31)$, which becomes a subject when knowledge is produced and synthesis is attained. Modern re-writing is thus a bit different from Lyotard's formulation. The goal there was to get at the truth such that infancy grows up once and for all into adulthood. When we move modern re-writing under the order of the beautiful, the goal is to get at as many truths as possible to keep in play the recursive passage from infancy to subjectivity. We listen to timbre, interrogate how we're hearing it and why, and imagine its infinite potentiality by naming it repeatedly.

Whereas the beautiful arouses pleasure from the experience of opening up the faculties, which activates the imagination, the sublime feeling is one of pleasure and displeasure, which incapacitates the imagination and the other faculties. The relation with thought to an object disintegrates. "Above and beyond the formal qualities that induced the quality of taste," Lyotard (1994) says, "thinking grasped by the sublime feeling is faced, 'in' nature, with quantities capable only of suggesting a magnitude or a force that exceeds its power of presentation" (75). The sublime is absolute, which means that it is not relative to anything else, and it is therefore without measure. The beautiful is immeasurable as it is experienced, which is what activates the imagination to play with how it could be measured. With the sublime, however, we are faced with the beyond of measure. Faced with the sublime, we experience our inability to accord forms and concepts, to understand and to know. "This powerlessness," he continues, "makes thinking deaf or blind." We try to present the sublime through the faculties at the limit of our ability to do so.

By approaching the limit, however, we feel the excessive surplus of thought and matter, that which can't be accorded a form. In the sublime, that is, "thinking defies its own finitude, as if fascinated by its own excessiveness. It is this desire for limitlessness that it feels in the sublime 'state': happiness and unhappiness" (55). This explains why Lyotard (1988), in the Wellek Library lectures, says that "thoughts are clouds:" because their "periphery... is as immeasurable 
as the fractal lines of Benoit Mandelbrot. They are pushed and pulled at variable speeds... One cloud casts its shadow on another, the shape of the cloud varies with the angle from which they are approached" (5). We can only ever touch thought; we can never know it.

Writing with and against language is a sublime experience because the writer uses words to articulate a thought but fails, and this effort and failure results in the experience of thought as such - thought beyond representation, knowledge, and language. While the infancy of "the beautiful allows one to hope for the advent of a subject," the sublime "seems to put an end to these hopes" (Lyotard 1994, 159-160). Re-writing modernity is the experience of a radical passibility to the phoné of words, where their matter works over the writer (or reader, speaker, or listener). The writer no longer tries to grasp phoné, and instead the words' timbres grasp the subject. Instead of a recursive state between infancy and subjectivity, then, re-writing modernity is the interruption of subjectivity by the force of childhood, the charge the suspends subjectivity. Asking the acousmatic writing question, we are stupefied: there is no subject to respond, nothing capable of synthesizing the meaning of the words, or of understanding the potentiality of the timbre. We can only be touched by it; matter can only pass through it. To be sure, writing isn't a pure state of passivity, but passibility. Passivity is a state of inaction. One lets things happen. To be passable is to be actively passive: to try to listen for that which will pass through us without being heard. In writing against language, we try to become passible to nuances; we try to start, continue, and finish sentences.

\section{Becoming passible to the timbre of words}

To think through the paradox of trying for passibility, we can approach words and language as a relation between matter and form. Literacy is generally engaged as a process of giving form to matter: there is data that we sense or think, and literacy is the mechanism through which we translate this into form. Literacy, on this reading, is the reduction of the timbre of words to an essence and the contraction of thought to knowledge. The timbre of words, however, can't be grasped by the writer, who instead must obey a demand for passibility. Listening to listening entails remaining within "an inexhaustible network linking listening to belonging, to the sense of obligation, a passivity I should like to translate as passibility" (Lyotard 1991, 178). In other words, this isn't a passive state in which the force of words determines the movement of the body (hands, fingers, wrists, arms, backs) at the computer. This would remain within the order of the beautiful as there would be a fit between form (writing) and matter (words). Instead, passibility is an attempt to obey the mute timbre of words as they manifest through language.

Within a musical composition of notes or linguistic composition of words, nuance is hard to detect. What we have to try to do is "suspend the activity of comparing and grasping, the aggressivity, the 'hands-on' [manicipium] and the negotiation that are the regime of the mind," at which point "it is perhaps not impossible to become open to the invasion of nuances, sensible to timbre" (139). Timbres, he says, "are what differ and defer," what "introduce a sort of infinity, the indeterminacy of the harmonics within the frame determined by this identity" of a word or a note (140). Within the composition as an actualization of music or language, timbres open up potentiality. For Lyotard, however, the point is not to name these timbres to show the endless meanings we can assign them. This would remain within modern re-writing and under the order of the beautiful. Accordingly, Eidsheim's (2019) pedagogy of assigning timbre "another name, and another, and another, and yet another" (193) works to deepen and expand the grasping. The 
endless assignment of new names loosens timbre's connection with essence but deepens its connection with knowledge and meaning. Timbre qua timbre remains inaccessible.

Instead of using the mind to create infinite understandings of timbre, the pedagogical task here is to suspend the mind, to enact "a mindless state of mind, which is required of mind not for matter to be perceived or conceived, given or grasped, but so that there be some something" (Lyotard 1991, 140). This is a shift from the drive to grasp what is happening to the experience of witnessing that something is happening, allowing the something to remain indeterminate. Timbre is that which deactivates the mind so that the "mind is accessible to the material event, can be 'touched' by it: a singular, incomparable quality — unforgettable and immediately forgotten" (141). The subject is disseized, and when the subject is recomposed there is only the feeling of a debt, an obligation to which the subject responds by continuing to try to write, to try to let thoughts disseize it yet again.

Whereas modern re-writing is infatuated with the infinite potential to actualize, re-writing modernity is possessed by the duty to have potentiality work over the writer, language, and the words. It is not just that words can have infinite interpretations or meanings, then, but that words are matter. At one point, Lyotard proffers that they are the matter-and not the form - of thoughts: "Perhaps words themselves, in the most secret place of thought, are its matter, its timbre, its nuance, i.e. what it cannot manage to think. Words 'say', sound, touch, always 'before' thought' (142). If this is obscure, and to me it is, then it is precisely a kind of sublime experience in which we're faced with the limits of our faculties: we can only think about the matter of words, we can only be passible to the matter of words. We can never know or name their matter.

Instead of only asking after the different potential meanings timbre can take, then, such a pedagogy asks teachers and students to listen for the beyond of meaning, for what we can't hear in a word or a sound, a text or a voice. Instead of being charged with interpretation, in which the mind tries to grasp matter according to existing knowledges or in order to produce new knowledges, when pedagogy is subjected to timbre we're confronted with our inability to accord matter a representation, assign it a category, or subsume it under a knowledge. Matter appears as a pedagogical agent on its own terms, disseizing the subject, disabling the grasping drive, and, hopefully, inaugurating a new non-hierarchical audible field. Yet this doesn't entail an eclipse of identity, as if a new audible field could be generated outside of the material conditions of the present. As such, the acousmatic questions, "What or who am I hearing" and "Who am I who hears this"- - both of which lead to the identification of the sonic and the subject in ways that can either re-entrench existing orders or reveal the infinite potentiality of timbre - are supplemented by another set: "What or who am I not hearing," "How can these inaudible sounds appear?"

\section{References}

Eidsheim, N.S. (2019). The Race of Sound: Listening, Timbre and Vocality. Durham: Duke University Press.

Ford, D.R. (2014). "A Critical Pedagogy of Ineffability: Identity, Education, and the Secret Life of Whatever." Educational Philosophy and Theory 46 (4): 380-392.

Gallagher, M., Hackett, A., \& Procter, L. (2018). "Vibrations in Place: Sound and Language in Early Childhood Literacy Practices.” Educational Studies 54 (4): 465-482.

Gershon, W.S. (2011). "Embodied Knowledge: Sounds as Educational Systems.” Journal of Curriculum Theorizing 27 (2): 66-81. 
Gershon, W.S. (2018). "Reverberations and Reverb: Sound Possibilities for Narrative, Creativity, and Critique." Qualitative Inquiry (online first):

Gershon, W.S., \& Applebaum, P. (2018). "Resounding Education: Sonic Instigations, Reverberating Foundations." Educational Studies 54 (4): 357-366.

Glissant, É. (1990/1997). Poetics of Relation, trans. B. Wing. Ann Arbor: The University of Michigan Press.

Hao, R.N. (2011). Rethinking Critical Pedagogy: Implications on Silence and Silent Bodies.” Text and Performance Quarterly 31 (3): 267-284

Lyotard, J-F. (1988). Peregrinations: Law, Form, Event. New York: Columbia University Press.

Lyotard, J-F. (1991). The Inhuman: Reflections on Time, trans. G. Bennington and R. Bowlby. Stanford: Stanford University Press.

Lyotard, J-F. (1992). "Voices of a Voice," trans. G.V.D. Abbeele. Discourse 14 (1): 126-145.

Lyotard, J-F. (1993). The Postmodern Explained: Correspondence 1982-1985, trans. D. Barry, B. Maher, J. Pefanis, V. Spate, and M. Thomas. Minneapolis: University of Minnesota Press.

Lyotard, J-F. (1994). Lessons on the Analytic of the Sublime, trans. Elizabeth Rottenberg. Stanford: Stanford University Press.

Mazzei, L.A., \& Jackson, A.Y. (2017). "Voice in the Agentic Assemblage." Educational Philosophy and Theory 49 (11): 1090-1098.

Mulcahy, D. (2012). "Affective Assemblages: Body Matters in the Pedagogy Practices of Contemporary School Classrooms.” Pedagogy, Culture \& Society 20 (1): 9-27.

Reddington, J., \& Price, D. (2018). "Pedagogy of New Materialism: Advancing the Educational Inclusion Agenda for Children and Youth with Disabilities." Disability Studies Quarterly 38 (1): n.p.

Snaza, N., \& Karavanta, M. (2015). "Human Remains.” Symploke 18 (4): 81-100.

Schwarz-Franco, O. (2018). "Polyphonic Teaching: The Ability to Facilitate Multiple Voices as a Crucial Teaching Skill.” Educational Studies 54 (4): 429-447.

Wargo, J.M. (2018). "Earwitnessing (In)Equity: Tracing the Intra-Active Encounters of 'Beingin-Resonance-with' Sound and the Social Contexts of Education." Educational Studies 54 (4)" 382-395.

Wozolek, B. (2018). "In 8100 Again: The Sounds of Students Breaking.” Educational Studies 54 (4): 367-381.

Zembylas, M. (2017). "The Contribution of Non-representational Theories in Education: Some Affective, Ethical and Political Implications." Studies in Philosophy and Education 36 (4): 393-407.

Zembylas, M., \& Michaelides, P. (2004). "The Sound of Silence in Pedagogy.” Educational Theory 54 (2): 193-210. 